\title{
In Search of Effective UiO-66 Metal-Organic Frameworks for Artificial Kidney Application
}

\author{
Klaudia Dymek, Grzegorz Kurowski, Łukasz Kuterasiński, Roman Jędrzejczyk, Magdalena Szumera, \\ Maciej Sitarz, Anna Pajdak, Łukasz Kurach, Anna Boguszewska-Czubara, and Przemysław J. Jodłowski*
}

Cite This: ACS Appl. Mater. Interfaces 2021, 13, 45149-45160

Read Online

ABSTRACT: The removal of uremic toxins from patients with acute kidney injury is a key issue in improving the quality of life for people requiring peritoneal dialysis. The currently utilized method for the removal of uremic toxins from the human organism is hemodialysis, performed on semipermeable membranes where the uremic toxins, along with small molecules, are separated from proteins and blood cells. In this study, we describe a mixed-linker modulated synthesis of zirconium-based metal-organic frameworks for efficient removal of uremic toxins. We determined that the efficient adsorption of uremic toxins is achieved by optimizing the ratio between -amino functionalization of the UiO-66 structure with $75 \%$ of $-\mathrm{NH}_{2}$ groups within organic linker structure. The maximum adsorption of hippuric acid and 3-indoloacetic acid

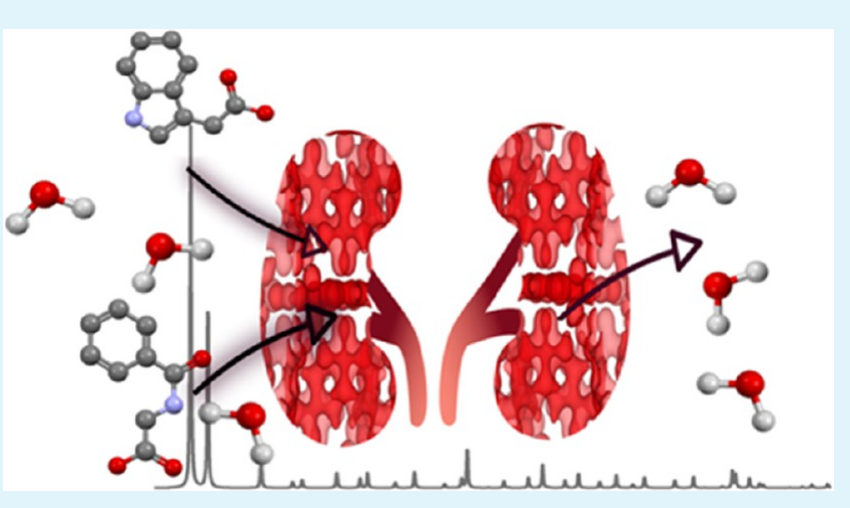
was achieved by UiO-66- $\mathrm{NH}_{2}(75 \%)$ and by $\mathrm{UiO}-66-\mathrm{NH}_{2}(75 \%) 12.5 \% \mathrm{HCl}$ prepared by modulated synthesis. Furthermore, UiO$66-\mathrm{NH}_{2}(75 \%)$ almost completely adsorbs 3-indoloacetic acid bound to bovine serum albumin, which was used as a model protein to which uremic toxins bind in the human body. The high adsorption capacity was confirmed in recyclability test, which showed almost $80 \%$ removal of 3-indoloacetic acid after the third adsorption cycle. Furthermore, in vitro cytotoxicity tests as well as hemolytic activity assay have proven that the UiO-66-based materials can be considered as potentially safe for hemodialytic purposes in living organisms.

KEYWORDS: metal-organic frameworks, $\mathrm{UiO}-66, \mathrm{UiO}-66-\mathrm{NH}_{2}$, uremic toxins, adsorption

\section{INTRODUCTION}

Acute kidney injury (AKI), formerly defined as acute renal failure, is a serious disease in which disorders in the glomerular filtration rate lead to the accumulation of the products of metabolisms in the human body. ${ }^{1}$ The products that would normally be filtered by the kidneys are called uremic toxins. ${ }^{2}$ The groups of uremic toxins consist of a large number of molecules that are divided into three main groups varying in molecular weight $-<500 \mathrm{D}, \geq 500 \mathrm{D}$, and having the ability of protein binding and water solubility. ${ }^{2}$ The uremic toxins represent a wide variety of molecules from organic groups including ribonucleosides, guanidines, polyols, purines, indoles, and polyamines. ${ }^{2}$ The multitude and diversity of their physicochemical properties require highly effective uremic toxin removal methods to improve the quality of life for endstate renal disease patients (ESRD). Currently, the most commonly used method for the removal of uremic toxins from the organisms of patients with ESRD is hemodialysis (HD). In this process, the patient's blood passes through semipermeable membranes and the small molecules are separated from proteins and blood cells. ${ }^{2}$ The membranes that are currently in use are made of cellulose/modified cellulose, polyamide, or polyacrylonitrile. ${ }^{2}$ Apart from $\mathrm{HD}$ and transplant methods, a wearable artificial kidney option (WAK) is actually under intense investigation. ${ }^{3}$ The advantage of WAK over conventional hemodialysis methods is the minimization of the need for hospital care, resulting in an improvement in the quality of life of people requiring peritoneal dialysis.

Despite the development of complex artificial kidneys that could improve the quality of life of people with severe renal injury, the development of novel adsorbent materials for the efficient removal of uremic toxins is critical to further develop care for patients with AKI.

From among the literature reports on the use of materials such as zeolites, ${ }^{4}$ carbon nanotubes, ${ }^{5}$ ordered mesoporous carbon, ${ }^{6}$ and metal-organic frameworks (MOF) ${ }^{7-10}$ the latter seems to be a relatively unexplored area. Although metal-

Received: April 2, 2021

Published: September 14, 2021 

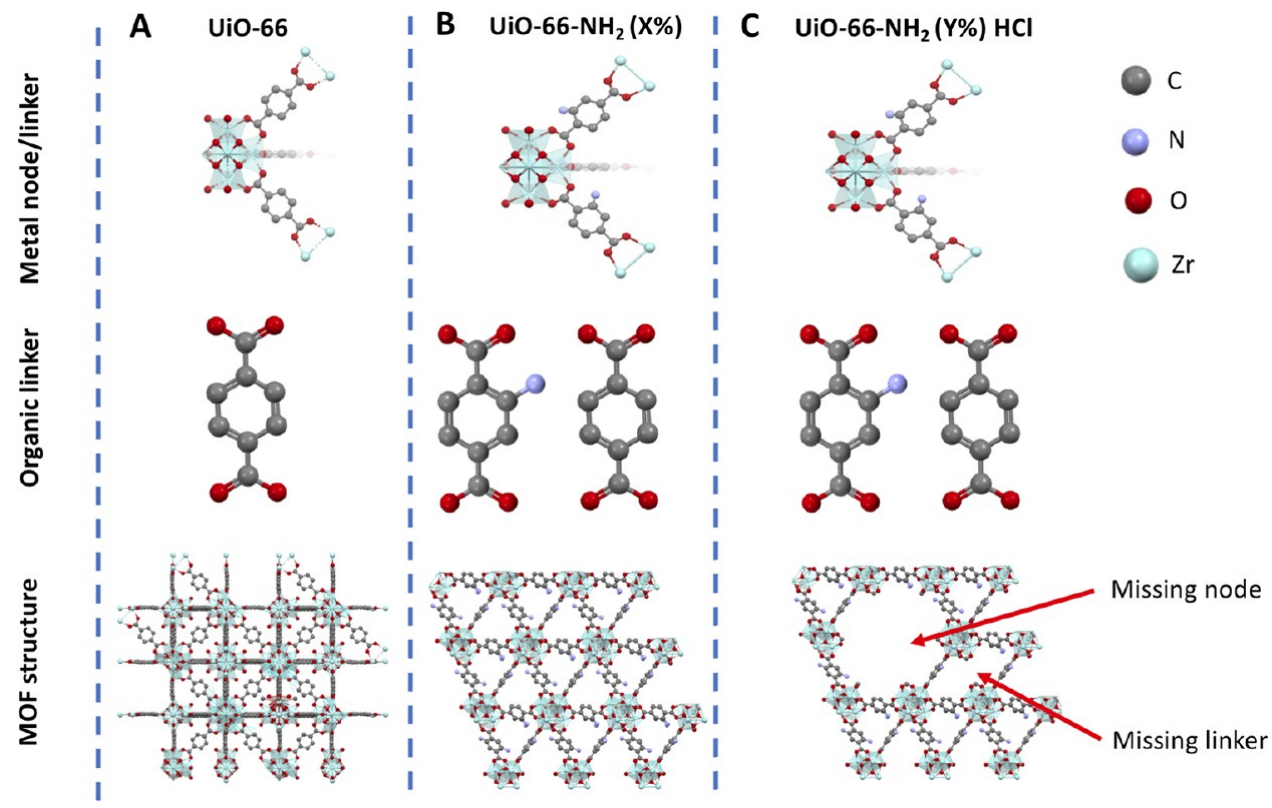

Figure 1. Structures of (A) UiO-66, (B) UiO-66- $\mathrm{NH}_{2}$, and (C) defective UiO-66- $\mathrm{NH}_{2} ; \mathrm{X} \%$ - wt \% of $\mathrm{H} 2 \mathrm{BDC}-\mathrm{NH}_{2}$ used; $\mathrm{Y} \%$ vol \% of $\mathrm{HCl}$ used during the synthesis.

organic frameworks have been successfully used in various applications including gas adsorption and separation, adsorption of toxins, ${ }^{11,12}$ environmental protection, ${ }^{13,14}$ catalysis, ${ }^{15-17}$ medicine, and drug release, ${ }^{12,18}$ their use as effective adsorbents of uremic toxins is currently undergoing intensive research. $^{7-10}$

Among literature reports, several MOFs have been investigated as potential adsorbents for uremic toxins. In the work by Cuchiaro et al., ${ }^{8}$ the adsorption efficiency of zirconium-based metal-organic framework MOF-808 and its iron analogue MIL-100(Fe) was tested in adsorption of $p$ cresyl sulfate. The maximum adsorption for MOF-808 and MIL-100(Fe) was 23.6 and $68.6 \mathrm{nmol} / \mathrm{mg}$ of $\mathrm{MOF}$, respectively. The greater sorption efficiency of MIL-100(Fe) was hypothetically attributed to the direct coordination of uremic toxins to the vacant metal sites available in the MOF structure. In the work by Kato et al., ${ }^{9}$ the zirconium-based metal-organic framework represented by NU-1000 was examined in the adsorption of potassium $p$-cresyl sulfate, potassium indoxyl sulfate, and hippuric acid. The maximum sorption of $0.1 \mathrm{mM}$ uremic toxins on $6 \mathrm{mg}$ of NU-1000 was achieved for hippuric acid and potassium indoxyl sulfate after 5 $h$, whereas for potassium $p$-cresyl sulfate, the maximum sorption after $5 \mathrm{~h}$ was equal to $80 \%$.

A high creatinine adsorption capacity was also reported for $\mathrm{UiO}-66-(\mathrm{COOH})_{2} /$ cotton fabric composite in the work by Abdelhameed et al. ${ }^{19}$ In their work, the UiO-66- $(\mathrm{COOH})_{2}$ was grown directly within cotton fabric. The Zr-based MOF/ cotton fabric composite material was tested in the adsorption of creatinine from a Tyrode buffer solution. The prepared material exhibited 113.6 and $192.3-212.8 \mathrm{mg} / \mathrm{g}$ sorption capacities for parent $\mathrm{UiO}-66-(\mathrm{COOH})_{2}$ and composite $\mathrm{UiO}$ 66- $(\mathrm{COOH})_{2} /$ cotton fabric, respectively. The UiO-66$(\mathrm{COOH})_{2} /$ cotton fabric materials also exhibited high creatinine adsorption recyclability.

Among the range of potential MOF structures with high adsorption parameters and high chemical resistance, UiO-66 seems to be very attractive due to its high thermal and chemical stability. In addition, the possibility of its modification by the incorporation of functional groups and optimization of the pore size by modulated synthesis makes UiO-66 a potential candidate for use in the sorption of uremic toxins. Recently, the adsorption of potassium p-cresyl sulfate, potassium indoxyl sulfate, and hippuric acid was tested in the work by Kato et al. ${ }^{9}$ over pristine $\mathrm{UiO}-66$. The maximum removal efficiencies reached during the sorption of $1.5 \mathrm{mg}$ of UiO-66 in $0.1 \mathrm{mM}$ potassium $p$-cresyl sulfate, potassium indoxyl sulfate or hippuric acid were 2.1, 21, and 90\%, respectively. However, it must be emphasized that the structure of the UiO-66 prepared in this work was nearly defect-free, which may considerably decrease the sorption capacity. ${ }^{18}$ Additionally, the modification of pristine UiO-66 by the incorporation of isovalent substituents such as $-\mathrm{NH}_{2}$, $-\mathrm{OH}$, and $\mathrm{SO}_{2} \mathrm{H}$ considerably increases sorption capacity by changing the electronic properties of the framework. ${ }^{20}$

In this work, we present a systematic approach to obtaining UiO-66 materials with varying concentration of -amino groups in parallel with defect engineering by the addition of concentrated hydrochloric acid during modulated synthesis. Since the preparation of the -amino-functionalized UiO-66 materials has been recently reported in a few papers, ${ }^{20-22}$ the information about the influence of the modulator addition on specific adsorption parameters optimized during the modulated synthesis is rather limited. The schematic representation of the crystal structures of mixed-linker and defective UiO-66 samples in "idealized" form is presented in Figure 1. The mixed-linker UiO-66- $\mathrm{NH}_{2}$ crystal structure is presented in Figure 1B. It must be pointed out that despite the fact that the amount of the -amino groups is defined by their amount during the synthesis step, their location in the resulting MOF structure and the sequence of occurrence in the crystal structure is stochastic rather than purely sequential. An additional aim of this paper is to combine both the presence of the specified amounts of $-\mathrm{NH}_{2}$ groups and the structural defects shown in idealized form (Figure 1C). 
Table 1. Synthesis Details and Low-Temperature $\mathrm{N}_{2}$ Sorption Results

\begin{tabular}{|c|c|c|c|c|c|c|c|}
\hline sample & $\begin{array}{l}\text { theoretical } \mathrm{mol} \mathrm{\%} \text { of } \mathrm{H}_{2} \mathrm{BDC} \text { - } \\
\mathrm{NH}_{2}\end{array}$ & $\begin{array}{l}\text { exp. mol \% of } \mathrm{H}_{2} \mathrm{BDC}- \\
\mathrm{NH}_{2}\end{array}$ & $\begin{array}{l}S_{\mathrm{BET}} \\
\mathrm{m}^{2} / \mathrm{g}\end{array}$ & $\begin{array}{l}S_{\text {Lang. }} \\
\mathrm{m}^{2} / \mathrm{g}\end{array}$ & $\begin{array}{l}V_{\text {micro }}^{a}, \\
\mathrm{~cm}^{3} / \mathrm{g}\end{array}$ & $D^{b}, \AA$ & $\begin{array}{l}\text { particle size } \\
\mathrm{nm}\end{array}$ \\
\hline $\mathrm{UiO}-66$ & n.a. & n.a. & 1072.8 & 1328.8 & 0.545 & 19.23 & $532.4 \pm 0.2$ \\
\hline $\mathrm{UiO}-6612.5 \% \mathrm{HCl}$ & n.a. & n.a. & 1132.6 & 1496.1 & 0.568 & 23.26 & $378.8 \pm 3.3$ \\
\hline $\mathrm{UiO}-6625 \% \mathrm{HCl}$ & n.a. & n.a. & 1241.5 & 1547.0 & 0.626 & 23.87 & $291.6 \pm 11.7$ \\
\hline $\mathrm{UiO}-66-\mathrm{NH}_{2}(25 \%)$ & 25 & 32 & 993.6 & 1228.7 & 0.487 & 19.49 & $802.6 \pm 27.9$ \\
\hline $\mathrm{UiO}-66-\mathrm{NH}_{2}(50 \%)$ & 50 & 49 & 936.4 & 1142.4 & 0.443 & 19.60 & $843.1 \pm 38.5$ \\
\hline UiO-66- $\mathrm{NH}_{2}(75 \%)$ & 75 & 68 & 929.9 & 1136.0 & 0.465 & 19.21 & $608.5 \pm 18.7$ \\
\hline $\mathrm{UiO}-66-\mathrm{NH}_{2}(100 \%)$ & 100 & 82 & 801.4 & 933.6 & 0.397 & 18.88 & $515.1 \pm 3.9$ \\
\hline $\begin{array}{l}\mathrm{UiO}-66-\mathrm{NH}_{2}(75 \%) \quad 12.5 \% \\
\mathrm{HCl}\end{array}$ & 75 & 71 & 947.4 & 1124.1 & 0.484 & 19.04 & $414.7 \pm 7.5$ \\
\hline $\mathrm{UiO}-66-\mathrm{NH}_{2}(75 \%) 25 \% \mathrm{HCl}$ & 75 & 52 & 1062.5 & 1208.5 & 0.512 & 18.77 & $313.3 \pm 4.7$ \\
\hline
\end{tabular}

${ }^{a}$ Total pore volume calculated from the NLDFT model. ${ }^{b}$ Average pore diameter calculated from the BET model. ${ }^{c}$ Particle size determined from the DLS analysis.

Understanding the adsorption of uremic toxins over metalorganic frameworks to further optimize their sorption properties requires a complementary approach that considers structural and morphological properties. Literature findings do not differentiate between the high surface area of prepared MOF and their electronic properties but rather attempt to rationalize MOF synthesis in both properties.

Taking into consideration economic factors, we would like to focus on the optimization of the synthesis of defective UiO66 to obtain highly efficient adsorbents of uremic toxins. To achieve that, we present the method of obtaining a series of UiO-66 metal-organic frameworks with optimized morphology by increasing the number of structural defects and electronic properties by functionalizing 1,4-benzene-dicarboxylate linkers by $-\mathrm{NH}_{2}$ groups. The complementary approach to the engineering of defective metal-organic frameworks allowed us to obtain materials with high affinity for uremic toxins and low-toxicity profile versus experimental models for epithelium cells and red blood cells (RBCs).

\section{EXPERIMENTAL SECTION}

The details of material synthesis and activation are described in detail in the Supporting Information. A detailed description of the characterization methods, including PXRD, UV-Vis, DR UV-Vis, DLS, $S_{\text {BET }}$, dissolution/liquid ${ }^{1} \mathrm{H}$ NMR, SEM, in situ DRIFT, DSCTGA, simulation (PXRD and electron densities), in vivo and in vitro tests, is provided in the Supporting Information. The synthesis details of all prepared samples are summarized in Table S1.

\section{RESULTS}

We synthesized the series of pristine and defective UiO-66 and $\mathrm{UiO}-66-\mathrm{NH}_{2}$ varying the content of hydrochloric acid used as a modulator and $\mathrm{H}_{2} \mathrm{BDC}$ and $\mathrm{H}_{2} \mathrm{BDC}-\mathrm{NH}_{2}$ in mixed-linker synthesis. The PXRD patterns for pristine and defective UiO66 samples (Figure S1) are in good agreement with the literature data ${ }^{23,24}$ and simulated PXRD patterns ${ }^{25}$ (Figures S1 and S2). Additionally, high-crystallinity materials were obtained for mixed-linker UiO-66 synthesis (Figure S1B), and defective $\mathrm{UiO}-66-\mathrm{NH}_{2}(75 \%) 25 \% \mathrm{HCl}$ and $\mathrm{UiO}-66-\mathrm{NH}_{2}$ (75\%) $12.5 \% \mathrm{HCl}$ showed no difference in PXRD diffractograms in comparison with the pristine $\mathrm{UiO}-66$ sample and defective UiO-66 X\% $\mathrm{HCl}$ (Figure S1A).

Quantitative UV-vis analysis of the -amino-functionalized UiO-66 previously proposed by Chavan et al. ${ }^{21}$ showed that the determined $\mathrm{H}_{2} \mathrm{BDC}-\mathrm{NH}_{2}$ content corresponds with theoretical values (Tables 1 and S2, Figure S3). Slight deviations between the experiment and theoretical contents of $\mathrm{H}_{2} \mathrm{BDC}-\mathrm{NH}_{2}$ in the prepared samples were observed while increasing the $-\mathrm{NH}_{2}$ content in mixed-linker synthesis (UiO$66-\mathrm{NH}_{2}(25-100 \%)$ ) and became considerable in UiO-66$\mathrm{NH}_{2}(75 \%) 25 \% \mathrm{HCl}$ and $\mathrm{UiO}-66-\mathrm{NH}_{2}(75 \%) 12.5 \% \mathrm{HCl}$ samples. We seek the cause of this in the fact that these samples were prepared with a considerable amount of hydrochloric acid (25 and 12.5 vol \%) during modulated synthesis of $\mathrm{UiO}-66-\mathrm{NH}_{2}(75 \%)$.

To investigate the influence of the synthesis parameters on the structural properties, low-temperature nitrogen adsorption isotherms were performed and corresponding BET and Langmuir surface areas were calculated (Figure S4, Table 1). The BET surface area of pristine UiO-66 was $1073 \mathrm{~m}^{2} / \mathrm{g}$ with pore diameters of 5-9 and 14-18 A (cf. Figure S4). As expected, defective UiO-66 showed an increased sorption capacity. The addition of $\mathrm{HCl}$ caused the opening of a new free pore space in the material, which resulted in an increase in their specific surface area values. The considerable increase of $\mathrm{SSA}_{\mathrm{BET}}$ from $1073 \mathrm{~m}^{2} / \mathrm{g}$ (pristine UiO-66) to $1133 \mathrm{~m}^{2} / \mathrm{g}$ for UiO-66 $12.5 \% \mathrm{HCl}$ and to $1242 \mathrm{~m}^{2} / \mathrm{g}$ for UiO-66 $25 \% \mathrm{HCl}$ was determined. Additional pores with diameters in the range of 14-20 A were opened for $\mathrm{UiO}-6612.5 \% \mathrm{HCl}$ and 5-8 and 17-22 Å for UiO-66 25\% $\mathrm{HCl}$, respectively.

The functionalized UiO-66 with amine groups showed the reduction of nitrogen sorption capacity, which was caused by part of their previously free pore space. As the content of the -amino groups increased, the $S_{S A} A_{\mathrm{BET}}$ value decreased, and for the $100 \%$ substitution of $\mathrm{H}_{2} \mathrm{BDC}$ by $\mathrm{H}_{2} \mathrm{BDC}-\mathrm{NH}_{2}$, the $\mathrm{SSA}_{\mathrm{BET}}$ was equal to $801 \mathrm{~m}^{2} / \mathrm{g}$. We observed ambiguous changes in the pore size distribution and a decrease in total pore volume from $0.545 \mathrm{~cm}^{3} / \mathrm{g}(\mathrm{UiO}-66)$ to $0.397 \mathrm{~cm}^{3} / \mathrm{g}\left(\mathrm{UiO}-66-\mathrm{NH}_{2}\right.$ $(100 \%))$, which is in good agreement with the literature data. $^{21,26,27}$ The value of the average pore diameter in the defected samples decreased slightly with increasing $\mathrm{NH}_{2}$ percentage concentration.

The thermogravimetric analysis-differential scanning calorimetry (TGA/DSC) results are presented in Figure S5. The obtained TGA/DSC curves represent the characteristic shape for UiO-66 samples revealing a few percent mass loss at temperatures of approximately $100{ }^{\circ} \mathrm{C}$ associated with the removal of physisorbed water. The mass loss proceeds up to a temperature of approximately $250{ }^{\circ} \mathrm{C}$, where zirconium oxoclusters are dehydroxylated. ${ }^{28} \mathrm{~A}$ considerable mass loss is observed for all samples at approximately $350{ }^{\circ} \mathrm{C}$ and at $430-$ $490{ }^{\circ} \mathrm{C}$, which is associated with the decomposition of formate ligands ${ }^{28}$ (approximately $350{ }^{\circ} \mathrm{C}$ ) and $\mathrm{H}_{2} \mathrm{BDC}-\mathrm{NH}_{2}\left(430{ }^{\circ} \mathrm{C}\right.$ ) and $\mathrm{H}_{2} \mathrm{BDC}\left(430{ }^{\circ} \mathrm{C}\right),{ }^{21}$ respectively. The TGA/DSC for 

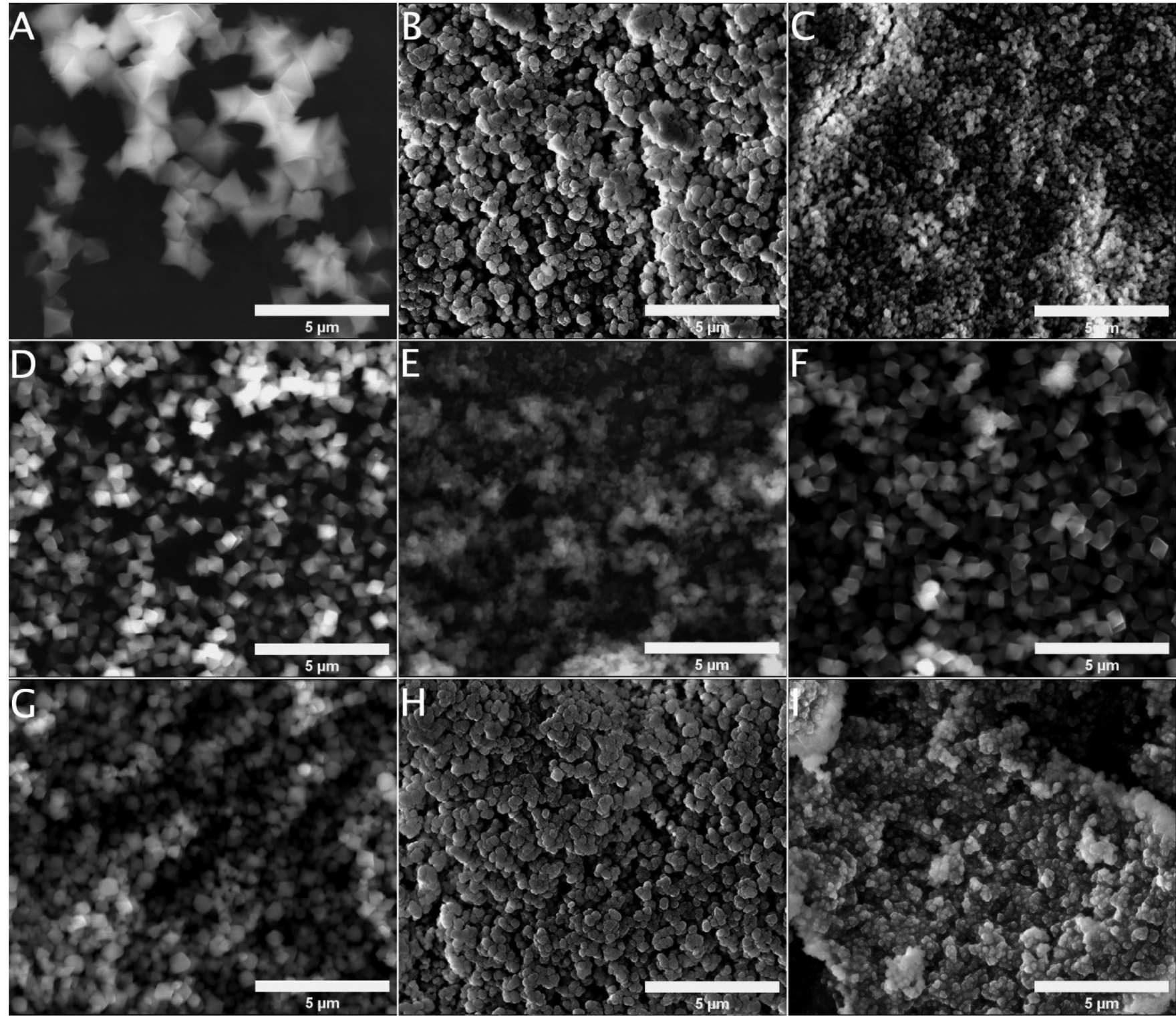

Figure 2. SEM micrographs of prepared samples: (A) UiO-66, (B) UiO-66 12.5\% HCl, (C) UiO-66 25\% HCl, (D) UiO-66-NH 2 (25\%) (E) UiO66- $\mathrm{NH}_{2}$ (50\%), (F) UiO-66- $\mathrm{NH}_{2}$ (75\%), (G) UiO-66- $\mathrm{NH}_{2}$ (100\%), (H) UiO-66- $\mathrm{NH}_{2}$ (75\%) $12.5 \% \mathrm{HCl}$, and (I) UiO-66-NH 2 (75\%) $25 \% \mathrm{HCl}$.

defective UiO-66 samples (Figure S5)-UiO-66, UiO-66 $12.5 \% \mathrm{HCl}$, and $\mathrm{UiO}-6625 \% \mathrm{HCl}$-shows similar trends in the TGA profile, although the defective $\mathrm{UiO}-6625 \% \mathrm{HCl}$ is considerably linker-deficient compared to the UiO-66 $12.5 \%$ $\mathrm{HCl}$ and UiO-66 samples, respectively.

The molecular structure of the prepared samples was determined by spectroscopic techniques including in situ DRIFT spectroscopy (Figure S6), dissolution ${ }^{1} \mathrm{H}$ NMR spectroscopy (Figures S7 and S8), and DR UV-Vis spectroscopy (Figure S9). The in situ DRIFT spectra for the parent for all prepared samples reveal a characteristic UiO-66 fingerprint in the $1750-650 \mathrm{~cm}^{-1}$ region with characteristic bands from the organic linker (Figure S6). The $\mathrm{UiO}-66-\mathrm{NH}_{2}$ samples prepared via the mixed-linker strategy reveal additional bands at approximately 3469 and $3386 \mathrm{~cm}^{-1}$ corresponding to asymmetric and symmetric $-\mathrm{NH}_{2}$ stretching modes (Figure $\mathrm{S} 6 \mathrm{~B}$ ). The intensity of those bands increases gradually with increasing $\mathrm{H}_{2} \mathrm{BDC}-\mathrm{NH}_{2}$ content used during the mixed-linker synthesis. The DRIFT spectra of defective $\mathrm{UiO}-66-\mathrm{NH}_{2}$ (75\%)
$25 \% \mathrm{HCl}$ and $\mathrm{UiO}-66-\mathrm{NH}_{2}(75 \%) 12.5 \% \mathrm{HCl}$ do not exhibit differences between their counterparts prepared without the addition of $\mathrm{HCl}$ during modulated synthesis.

The precise determination of the molecular structure of prepared samples was performed by the dissolution/liquid ${ }^{1} \mathrm{H}$ NMR method previously proposed by Shearer et al. ${ }^{28}$ The proposed method assumes the dissolution of the MOF framework in deuterated digestion medium and therefore identification of the organic linker, solvent, and modulator in prepared samples. The method also allows determination of whether the monocarboxylates compensate the defects in prepared samples (Figures S7 and S8 for as-received and activated samples, and Table S3). The representative spectrum of the pristine UiO-66 sample prepared with the addition of $9.2 \mathrm{~mL}$ of acetic acid is presented in Figure S8A with signals from $\mathrm{BDC}^{2-}$ (chemical shift $7.73 \mathrm{ppm}$ ) and from formate (ca. $8.3 \mathrm{ppm}$ ) and acetate groups (ca. $1.84 \mathrm{ppm}$ ). The dissolution ${ }^{1} \mathrm{H}$ NMR spectra for -amino-substituted samples (Figure $\mathrm{S} 8 \mathrm{~B}, \mathrm{C}$ ) reveal additional signals in a range of 7-7.73 ppm 
A

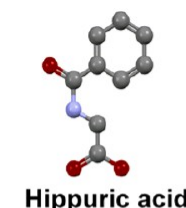

B

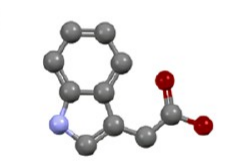

3-indoleacetic acid

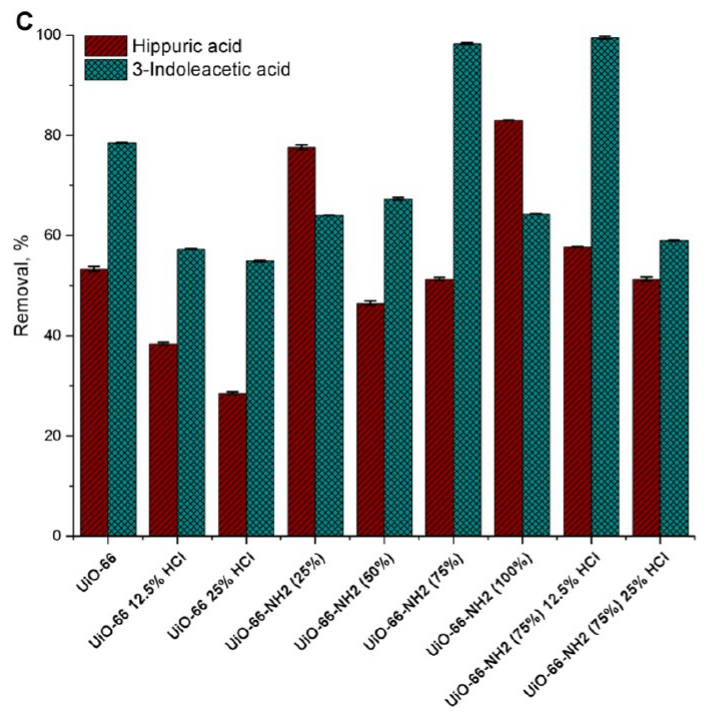

D

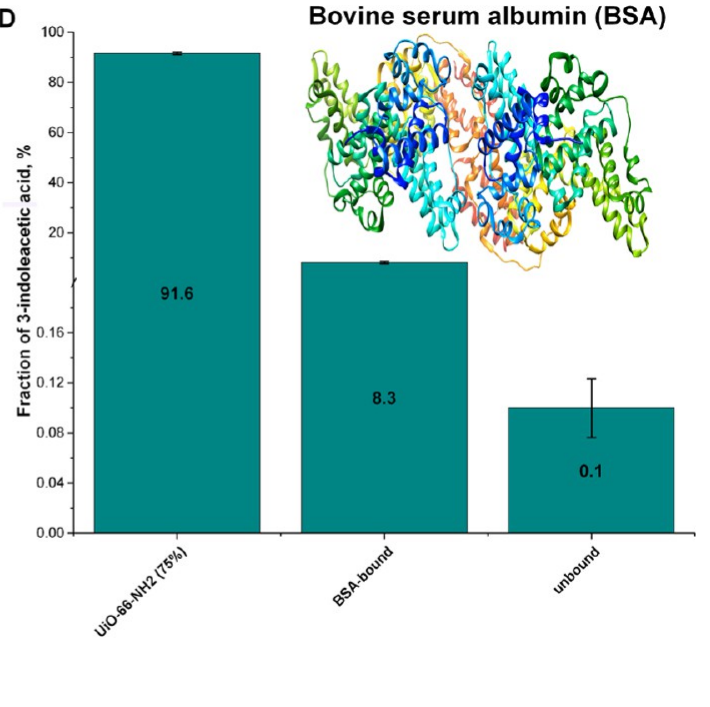

Figure 3. Structure of uremic toxins used in this study: (A) hippuric acid; (B) 3-indoloacetic acid; (C) removal efficiency of uremic toxins on prepared UiO-66-X samples; and (D) adsorption of 3-indoloacetic acid with $\mathrm{UiO}-66-\mathrm{NH}_{2}(75 \%)$ and bovine serum albumin (BSA) - $0.2 \mathrm{M} \mathrm{NaCl}$ aq. solution at $310 \mathrm{~K}$; hydrogens are omitted for clarity.

from BDC- $\mathrm{NH}_{2}{ }^{2-}$. It is worth mentioning that, in samples prepared with the addition of concentrated hydrochloric acid, the acetate signals of dissolution/liquid ${ }^{1} \mathrm{H}$ NMR were not detected, whereas in all samples, formate was detected in small amounts. Additionally, an increasing intensity of signals in a range of $7-7.73 \mathrm{ppm}$ originating from $\mathrm{BDC}-\mathrm{NH}_{2}{ }^{2-}$ was observed with increasing content of 2 -aminoterephthalic acid used during mixed-linker synthesis with a simultaneous decrease of intensity of $\mathrm{BDC}^{2-}$ originating from terephthalic acid. The $\mathrm{BDC}^{2-}$ signal disappears completely from $\mathrm{UiO}-66-$ $\mathrm{NH}_{2}$ (100\%), where only 2-aminoterephthalic acid was used during mixed-linker synthesis.

When considering the adsorption of the uremic toxins, the correlation of the crystal size together with their sorption capacities has to be considered. Detailed crystal sizes in a powder form and hydrodynamic diameters were determined by SEM and DLS analyses. The SEM microscopy (Figure 2) results showed that the morphology and size of prepared crystals are strongly influenced by the organic linker and modulator content used during the solvothermal synthesis. The pristine UiO-66 samples prepared with the addition of acetic acid exhibit octahedral morphology and crystal sizes in a range of $700-1600 \mathrm{~nm}$. The shape of $\mathrm{UiO}-6612.5 \% \mathrm{HCl}$ and $\mathrm{UiO}-6625 \% \mathrm{HCl}$ crystals changes significantly from octahedral UiO-66, and a tendency to form agglomerated oval crystals was noticed. The formation of regular octahedral crystals was observed for -amino-functionalized $\mathrm{UiO}-66-\mathrm{NH}_{2}$ crystals regardless of the content of $\mathrm{H}_{2} \mathrm{BDC}-\mathrm{NH}_{2}$. The crystal shape considerably changes for $\mathrm{UiO}-66-\mathrm{NH}_{2}$ as hydrochloric acid was used during the synthesis and their morphological parameters are close $\mathrm{UiO}-6612.5 \% \mathrm{HCl}$ and $\mathrm{UiO}-6625 \%$ $\mathrm{HCl}$ samples.

Together with SEM results, the hydrodynamic particle size of prepared samples in aqueous was determined (Table 1 and Figure S10). We observed a decrease in the particle size while comparing the hydrodynamic particle sizes of the pristine $\mathrm{UiO}$ 66 and $\mathrm{UiO}-6612.5 \% \mathrm{HCl}$ and $\mathrm{UiO}-6625 \% \mathrm{HCl}$ samples. The UiO-66 crystal size decreases for defective UiO-66 12.5\% $\mathrm{HCl}$ and $\mathrm{UiO}-6625 \% \mathrm{HCl}$ samples. The -amino-substituted $\mathrm{UiO}-$ 66 samples revealed considerably bigger crystal sizes from approximately $800 \mathrm{~nm}$ for $\mathrm{UiO}-66-\mathrm{NH}_{2}(25 \%)$ to $515 \mathrm{~nm}$ for UiO-66- $\mathrm{NH}_{2}(100 \%)$ showing a decreasing tendency with an increasing amount of -amino groups within the framework.

The adsorption efficiency of two common uremic toxins (hippuric acid and 3-indoloterephthalic acid) was examined on prepared $\mathrm{UiO}-66$, defective $\mathrm{UiO}-66$, and $\mathrm{UiO}-66-\mathrm{NH}_{2}$ samples. The adsorption efficiency results are presented in Figure 3, while detailed adsorption curves as a function of time and calculated pseudo-first-order and pseudo-second-order kinetic curves are presented in Figures S11-S16 and Tables S4 and S5. The modulated synthesis with concentrated hydrochloric acid resulted in a significant decrease in toxin adsorption. Despite an increase in structural parameter values (Table 1), application of the defect resulted in the destruction of binding sites for toxins. At the same time, functionalization of the UiO-66 material by $\mathrm{NH}_{2}$ resulted in ambiguous changes. Only some of the materials recorded a significant increase in toxin adsorption. The maximum adsorption capacity was achieved only for 3-indoloacetic acid for UiO-66- $\mathrm{NH}_{2}$ (75\%) and defective UiO-66- $\mathrm{NH}_{2}(75 \%) 12.5 \% \mathrm{HCl}$. Both materials exhibited a lower $\mathrm{SSA}_{\mathrm{BET}}$ value and a lower $V_{\text {micro }}$ value in comparison with pristine UiO-66 (Table 1). Nevertheless, the adsorption capacity of 3 -indoleacetic acid was $20-21 \%$ higher in these materials than in UiO-66. The reason for this may be that, despite a significant change in the volume of pores, their distribution has changed considerably, which resulted in an increase in diffusion resistance. The removal of 3-indoloacetic acid on the remaining MOF samples was in a $60-80 \%$ range. In the case of hippuric acid, the maximum uptake was achieved for $\mathrm{UiO}-66-\mathrm{NH}_{2}(100 \%)$ and $\mathrm{UiO}-66-\mathrm{NH}_{2}(25 \%)$ and was equal to 83 and $77 \%$, respectively. The rapid adsorption of hippuric acid on -amino-functionalized $\mathrm{UiO}-66$ samples can be observed in the first $10 \mathrm{~min}$ of adsorption (Figure S11B).

The search for efficient uremic toxin adsorbents must take into account the efficiency of the adsorption of uremic toxins to the human serum albumin (HSA). In patients with chronic kidney disease, approximately $80 \%$ of uremic toxins are bound to the HSA. To determine the adsorption efficiency of the 3indoloacetic acid bound to amino acids, we measured the removal of the 3 -indoloacetic bound to the bovine serum 
A

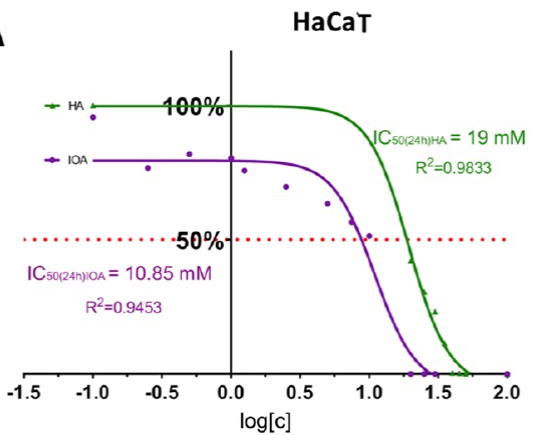

C

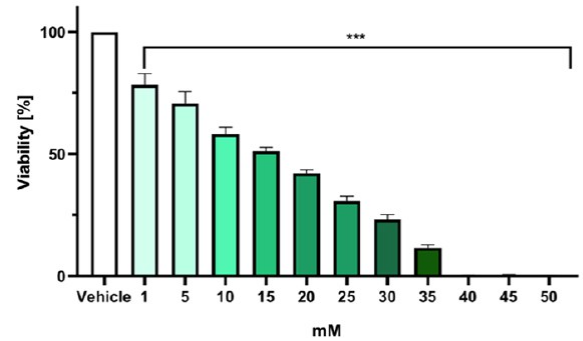

B

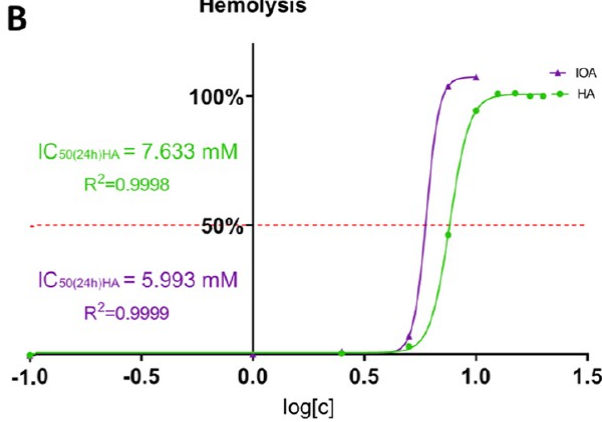

D

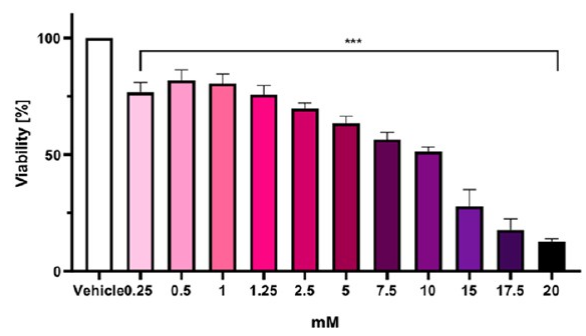

Figure 4. (A) Evaluation of $\mathrm{IC}_{50}$ for hippuric and 3-indoleacetic acids on $\mathrm{HaCaT}$ cell line and (B) evaluation of $\mathrm{IC}_{50}$ for hippuric acid and 3indoleacetic acid in hemolytic activity test. Viability (\%) results for hippuric (C) and 3-indoleacetic acids (D) on HaCaT cell line; mean values \pm SD, $* * * p<0.001$, Tukey test.

albumin (BSA). The BSA was used as a model system, similar to the HAS, since human serum albumin contains one tryptophan residue compared to two in BSA. The procedure of the determination of the removal of uremic toxin bound to serum albumin was adapted from the work of Kato et al. ${ }^{9}$ The results of the competitive adsorption of BSA-bound 3indoloacetic acid are shown in Figure 3D. To compare the results of the competitive adsorption and the amount of BSAbound 3-idoloacetic acid, we performed a blind trial without UiO-66- $\mathrm{NH}_{2}$ (75\%). We determined that $97 \pm 0.3 \%$ of 3 indoloacetic acid was bound to the BSA. After adding UiO-66$\mathrm{NH}_{2}(75 \%)$ to the solution, $91.6 \pm 0.48 \%$ was removed from the solution while the fractions of BSA-bound and BSAunbound were $8.3 \pm 0.48$ and $0.1 \pm 0.02 \%$, respectively.

To illustrate the effect of defect engineering on the adsorption ability of two most efficient samples UiO-66- $\mathrm{NH}_{2}$ (75\%) and $\mathrm{UiO}-66-\mathrm{NH}_{2}(75 \%) 12.5 \% \mathrm{HCl}$, the adsorption of 3 -indoloacetic acid was performed on alternated solid/liquid ratio. The results of the adsorption of 3-indoloacetic acid over $0.5 \mathrm{mg}$ of $\mathrm{UiO}-66-\mathrm{NH}_{2}$ (75\%) and UiO-66- $\mathrm{NH}_{2}$ (75\%) $12.5 \%$ $\mathrm{HCl}$ are shown in Figure S17. It may be seen that, for UiO-66$\mathrm{NH}_{2}(75 \%) 12.5 \% \mathrm{HCl}$, rapid uremic toxin removal may be observed in the first $20 \mathrm{~min}$ of the adsorption process, while for UiO-66- $\mathrm{NH}_{2}$ (75\%), the adsorption proceeds smoothly, reaching its maximum after $120 \mathrm{~min}$ of adsorption. The comparison between maximum adsorption of 3-indoloacetic acid on $\mathrm{UiO}-66-\mathrm{NH}_{2}$ (75\%) and $\mathrm{UiO}-66-\mathrm{NH}_{2}$ (75\%) $12.5 \%$ $\mathrm{HCl}$ shows that at the early stage of the adsorption process, an increased pore volume of $\mathrm{UiO}-66-\mathrm{NH}_{2}(75 \%) 12.5 \% \mathrm{HCl}$ favors rapid adsorption but results in a decrease in adsorption sites, which can be observed in a slightly decreased overall uremic toxin removal (approximately $20 \mu \mathrm{mol} / \mathrm{g}$ lower adsorption in comparison with $\mathrm{UiO}-66-\mathrm{NH}_{2}(75 \%)$ ).

The experimentally obtained equilibrium sorption data were also fitted into Langmuir and Freundlich adsorption isotherms (Figures S18 and S19, Table S6). The values of equilibrium adsorption were calculated from Langmuir and Freundlich equations (eqs 10 and 11, Supporting Information) and presented in terms of adsorption equilibrium constant $k_{\mathrm{L}}$ and adsorption capacity for the Langmuir model, and adsorption equilibrium constant $k_{\mathrm{F}}$ and $n$ for the Freundlich model. The coefficient of determination $R^{2}$ for both hippuric acid and 3indoloacetic acid adsorption isotherms is close to 1 for the Freundlich adsorption model.

The recyclability of $\mathrm{UiO}-66-\mathrm{NH}_{2}(75 \%)$ and $\mathrm{UiO}-66-\mathrm{NH}_{2}$ (75\%) $12.5 \% \mathrm{HCl}$ in subsequent cycles of adsorption of uremic toxins was determined for 3-indoloacetic acid (Figure S20). The recyclability of the adsorption on any of the adsorbent is an important feature that is required for the MOF materials to be considered for artificial kidney application. ${ }^{19}$ The adsorption of 3-indoloacetic acid on $\mathrm{UiO}-66-\mathrm{NH}_{2}$ (75\%) and $\mathrm{UiO}-66-\mathrm{NH}_{2}(75 \%) 12.5 \% \mathrm{HCl}$ on the first cycle was close to $100 \%$ and diminished smoothly after each of the recycling cycles. After the second adsorption cycle, the adsorption efficiency decreases to approximately $80 \%$ for UiO-66- $\mathrm{NH}_{2}(75 \%)$ and remains constant after the third cycle. For the UiO-66- $\mathrm{NH}_{2}$ (75\%) $12.5 \% \mathrm{HCl}$, the maximum adsorption reached after the second and third cycles was 76 and $70 \%$, respectively.

The final step was to check the safety of the prepared UiO66 materials; therefore, to fully confirm the low toxicological profile of UiO-66-based samples, we have applied for the first time in vitro experimental models for cytotoxicity toward cells potentially exposed to the direct contact with our materials, i.e., epithelial (HaCaT) and kidney (Vero, HEK-293) cell lines. $\mathrm{HaKaT}$ cells (keratinocyte cells) are found in the deepest basal layer of the stratified epithelium. In fact, they are the principal cell type of the epithelium and comprise about $90 \%$ of the total cell population of epithelium and even up to $95 \%$ of the cells in the epidermis. ${ }^{29}$ Noteworthy, $\mathrm{HaCaT}$ cells are the most commonly used cell lines for toxicological assessment. Vero and HEK-293 are normal kidney-derived cells, where Vero denotes kidney epithelial cells extracted from an African green monkey and HEK-293 denotes human embryonic kidney cells. 


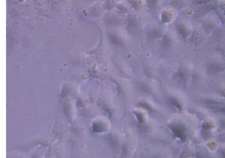

Vehicle

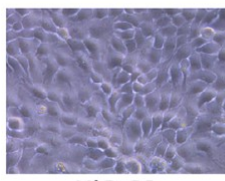

UiO-66

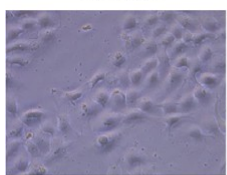

UiO-66 12.5\%HCl

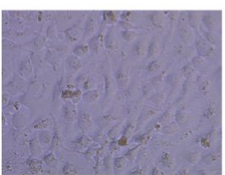

UiO-66 25\% HCl

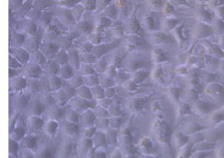

UiO-66- $\mathrm{NH}_{2}(25 \%)$

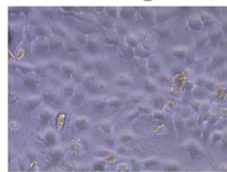

UiO-66- $\mathrm{NH}_{2}(50 \%)$
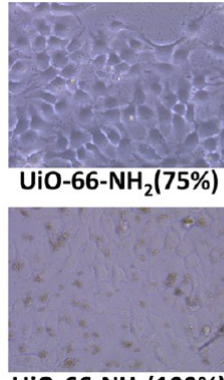

UiO-66- $\mathrm{NH}_{2}(100 \%)$

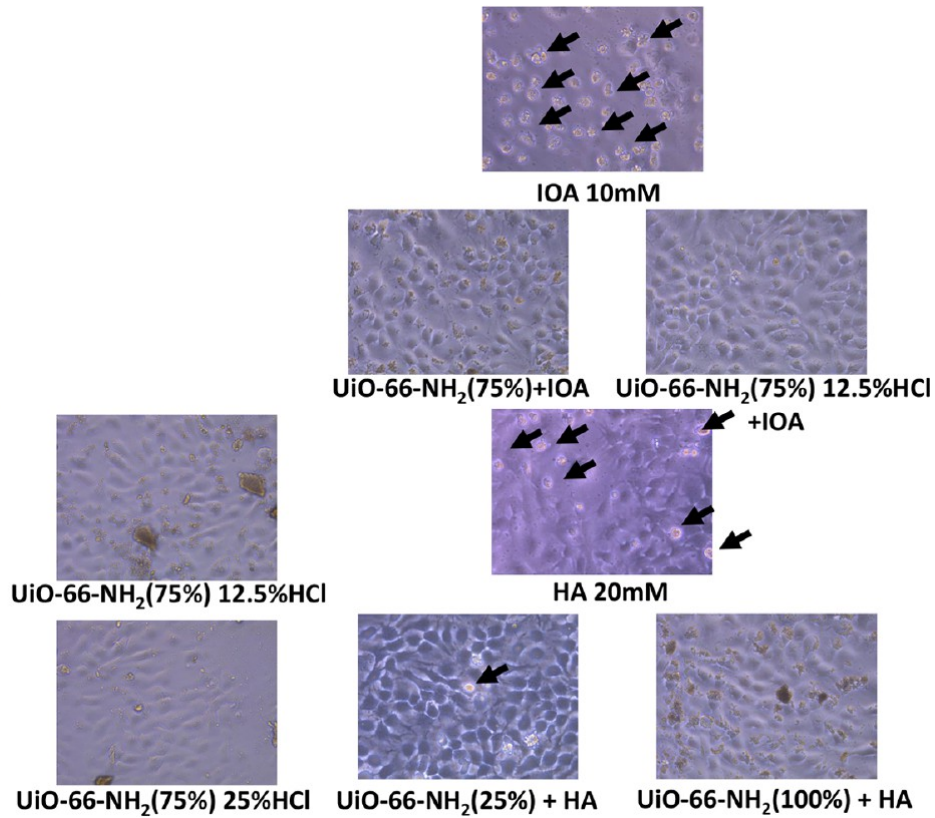

Figure 5. Images of $\mathrm{HaCaT}$ cells after $24 \mathrm{~h}$ treatment with UiO-66 samples without and with hippuric and 3-indoloacetic acids. Black arrows show dead cells.

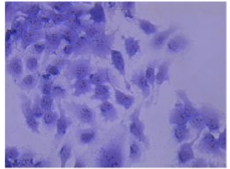

Vehicle

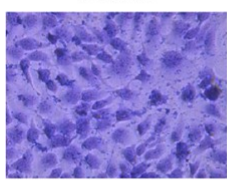

UiO-66

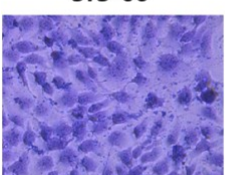

UiO-66 12.5\%HCl

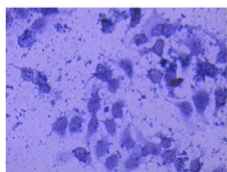

UiO-66 25\% HCl

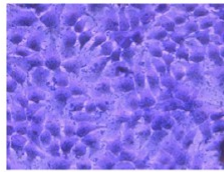

UiO-66- $\mathrm{NH}_{2}(25 \%)$

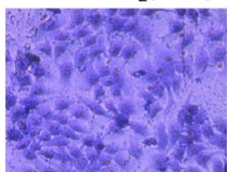

UiO-66- $\mathrm{NH}_{2}(50 \%)$

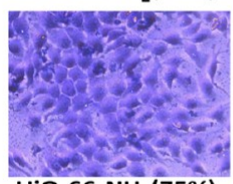

UiO-66- $\mathrm{NH}_{2}(75 \%)$

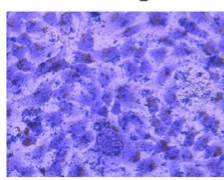

UiO-66- $\mathrm{NH}_{2}(100 \%)$
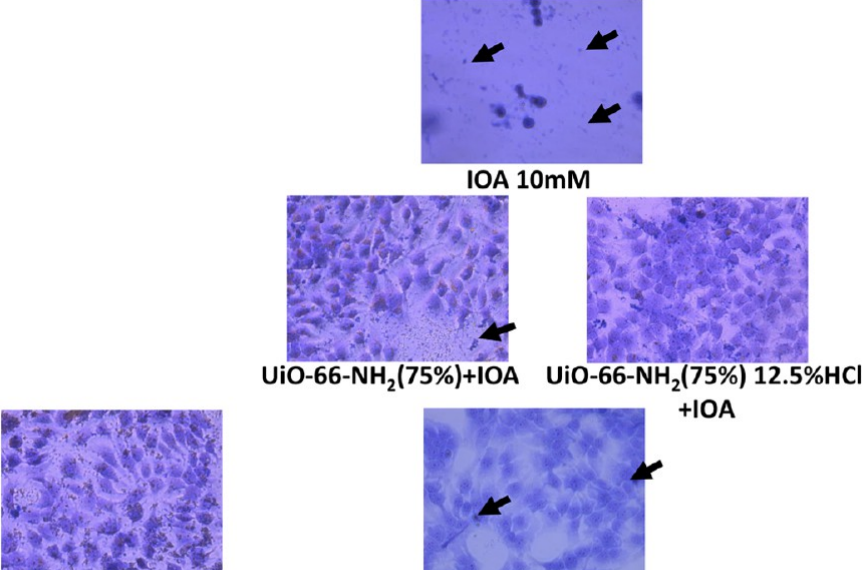

UiO-66- $\mathrm{NH}_{2}(75 \%) 12.5 \% \mathrm{HCl}$
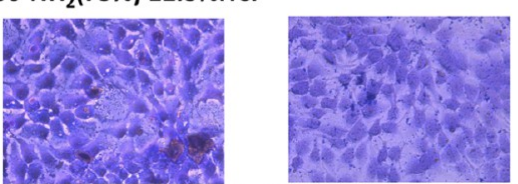

HA 20mM

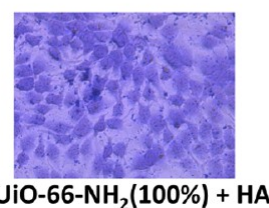

Figure 6. Images of $\mathrm{HaCaT}$ cells stained with $\mathrm{H} \& \mathrm{E}$ after $24 \mathrm{~h}$ treatment with $\mathrm{UiO}-66$ samples without and with hippuric and 3-indoloacetic acids. Black arrows show dead cells.

As the compounds used for hemodialysis have the greatest direct contact with blood, we decided to investigate the behavior of the tested compounds toward selected blood morphotic elements. If a compound shows toxicity to blood cells, then it cannot be used for hemodialysis purposes. Thus, the toxic effects of tested MOFs should be tested against RBCs with regard to the blood system prior to other cells it may have contact with. Hemolysis is connected with the disintegration of RBCs, and the test detects the leaking of hemoglobin, an important protein responsible for oxygen transport, into the plasma. When hemoglobin is released via hemolysis, it shows toxic effects on the vascular, myocardial, renal, and central nervous system tissues as a vasoactive and redox-active protein. ${ }^{30}$ Numerous studies have found good correlations between in vitro hemolysis tests and in vivo toxicity by the hemolytic effect. ${ }^{31}$ Thus, our study is the first investigation of the in vitro toxicity of UiO-66-based molecules using the outcomes of hemolysis tests to fully confirm their low toxicological profile.

The first step in that experiment was to evaluate $\mathrm{IC}_{50}$ values of exemplary uremic toxins for further studies. The evaluated values of $\mathrm{IC}_{50}$ were 19.71 and $7.633 \mathrm{mM}$ for hippuric acid (HA), and 11.25 and $5.993 \mathrm{mM}$ for 3-indoleacetic acid (IOA) for HaKaT and RBCs, respectively (Figure 4).

Then, we used these concentrations of uremic toxins (approximately $20 \mathrm{mM}$ for $\mathrm{HA}$ and $10 \mathrm{mM}$ for IOA) in the 


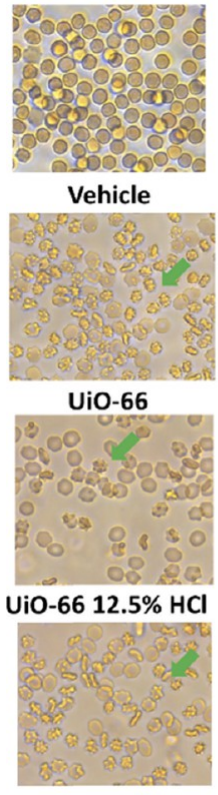

UiO-66 25\% HCl
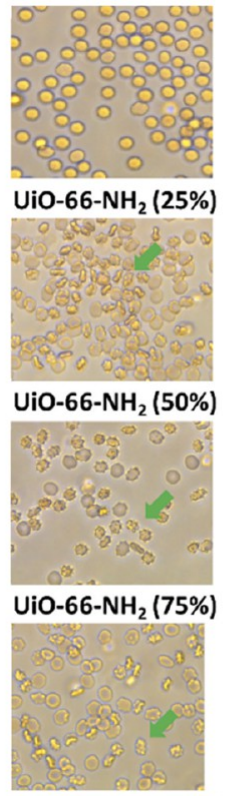

UiO-66- $\mathrm{NH}_{2}(100 \%)$

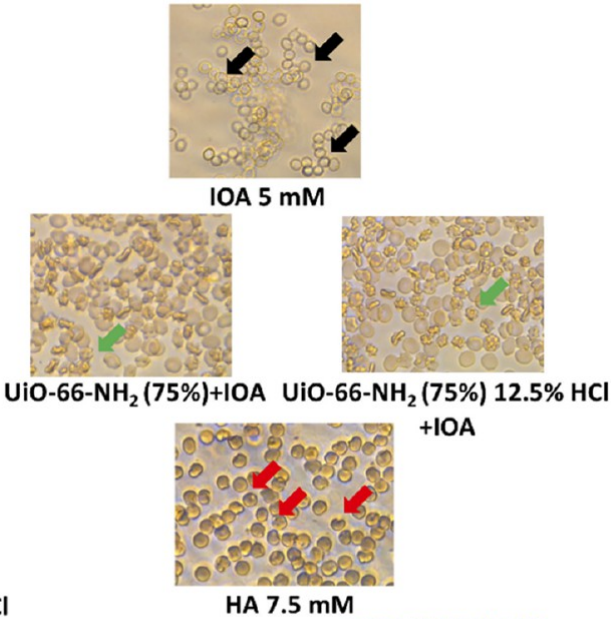

UiO-66- $\mathrm{NH}_{2}(75 \%) 12.5 \% \mathrm{HCl}$
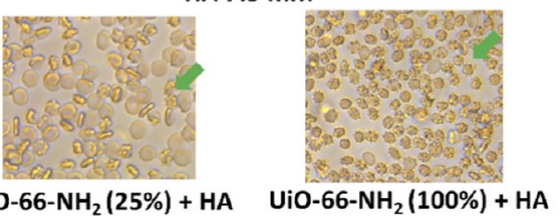

Figure 7. Images of the hemolytic activity test performed on human erythrocytes. Green arrows show echinocytes, red arrows show disintegrating erythrocytes, and black arrows show disintegrated erythrocytes.

experimental safety tests of UiO-66 samples versus epithelium cells. Thus, we incubated $\mathrm{HaCaT}$ cells with a series of UiO-66 materials at a concentration of $1 \mathrm{mg} / \mathrm{mL}$ without and with $\mathrm{HA}$ and IOA at their $\mathrm{IC}_{50}$ for $24 \mathrm{~h}$, and then we observed the morphology of cells to establish cell toxicity. Images of these cells without and with $\mathrm{H} \& \mathrm{E}$ staining (Figures 5 and 6) show that UiO-66 samples exert no cytotoxic effect on the cells. Moreover, we have observed their cytoprotective action against the activity of uremic toxins, which proves their effectiveness and safety of application.

To prove the low cytotoxicity of examined materials versus kidney cells and kidney epithelial cells, we performed the same experiment on the HEK-293 cell line and the Vero cell line. The obtained results (cf. Figures S21-S24, Table S7), similar to that in the case of $\mathrm{HaCaT}$ cells, finally confirmed the lowcytotoxicity profile of the tested compounds.

The results of our study (Figure 7, Table 2) proved the highsafety profile of examined compounds versus RBCs, as the

Table 2. Hemolytic Activity of the Prepared Samples

\begin{tabular}{|c|c|}
\hline sample & $\%$ of hemolysis (mean $\pm \mathrm{SD})$ \\
\hline $\mathrm{UiO}-66$ & $3.616 \pm 0.529$ \\
\hline $\mathrm{UiO}-6612.5 \% \mathrm{HCl}$ & $0.562 \pm 0.105$ \\
\hline $\mathrm{UiO}-6625 \% \mathrm{HCl}$ & $4.358 \pm 0.235$ \\
\hline $\mathrm{UiO}-66-\mathrm{NH}_{2}(25 \%)$ & $3.639 \pm 0.425$ \\
\hline $\mathrm{UiO}-66-\mathrm{NH}_{2}(50 \%)$ & $4.964 \pm 0.286$ \\
\hline $\mathrm{UiO}-66-\mathrm{NH}_{2}(75 \%)$ & $2.433 \pm 1.271$ \\
\hline $\mathrm{UiO}-66-\mathrm{NH}_{2}(100 \%)$ & $2.613 \pm 0.187$ \\
\hline $\mathrm{UiO}-66-\mathrm{NH}_{2}(75 \%) \quad 12.5 \% \mathrm{HCl}$ & $2.860 \pm 0.132$ \\
\hline $\mathrm{UiO}-66-\mathrm{NH}_{2}(75 \%) 25 \% \mathrm{HCl}$ & $3.616 \pm 0.529$ \\
\hline IOA $7.5 \mathrm{mM}$ & $91.165 \pm 3.215$ \\
\hline $\mathrm{UiO}-66-\mathrm{NH}_{2}(75 \%)+\mathrm{IOA}$ & $4.537 \pm 0.123$ \\
\hline $\mathrm{UiO}-66-\mathrm{NH}_{2}(75 \%) 12.5 \% \mathrm{HCl}+\mathrm{IOA}$ & $3.459 \pm 0.174$ \\
\hline HA $7.5 \mathrm{mM}$ & $44.010 \pm 2.303$ \\
\hline $\mathrm{UiO}-66-\mathrm{NH}_{2}(25 \%)+\mathrm{HA}$ & $2.329 \pm 0.370$ \\
\hline $\mathrm{UiO}-66-\mathrm{NH}_{2}(100 \%)+\mathrm{HA}$ & $2.007 \pm 0.125$ \\
\hline
\end{tabular}

percentage of hemolysis of RBCs exposed to UiO-66 showed hematological toxicity less than $5 \%$, while most of them did not exceed the value of $3 \%$ (cf. Table 2 ).

\section{DISCUSSION}

The present work is a systematic study connected with the search for effective materials based on the UiO-66 structure for artificial kidney application. Our results clearly demonstrate that effective sorption of uremic toxins is a derivative of a number of factors, ranging from the type of toxin, MOF structure, method of synthesis, structural parameters, particle size, and the type and concentration of functional groups in the MOF structure.

Starting from the determination of the crystallinity of prepared samples, at first glance, no differences in diffractograms were observed. The PXRD patterns revealed subtle changes coming from several structural changes in the structure of UiO-66-modified materials. The PXRD patterns revealed broad weak reflections at $2 \theta \sim 4$ and $6^{\circ}$, indicating the presence of missing-linker/cluster nanoregions in the prepared samples (Figure S1). ${ }^{32}$ This phenomenon was specifically observed for samples prepared during modulated synthesis with the addition of hydrochloric acid (cf. Figure $\mathrm{S} 1 \mathrm{~A}$ ) and defective -amino-functionalized samples (Figure S1C). Additionally, on PXRD for UiO-66- $\mathrm{NH}_{2}$ (100\%), we found considerable peak broadening, which suggests the presence of smaller crystals. ${ }^{26}$ Indeed, taking into account the results of the hydrodynamic particle size determined by DLS and SEM analyses, the tendency of formation of smaller crystals with an increasing content of 2-aminoterephthalic acid used during modulated synthesis was confirmed. The impact of modulator concentration or the zirconium source on crystal size and morphology has been recently reported in several papers. ${ }^{26,33,34}$ Schaate et al. $^{26}$ examined the influence of benzoic acid on $\mathrm{UiO}-66$ and $\mathrm{UiO}-66-\mathrm{NH}_{2}$ crystal size using the DLS method and XRD peak broadening. They found that, in the case of UiO-66, the crystal size increased with increasing 
amount of benzoic acid, which was a derivative of the formation of zirconium-benzoic acid complexes. Conversely, -amino-functionalized $\mathrm{UiO}-66-\mathrm{NH}_{2}$ was nearly unaffected by the addition of the modulator ( $0-30$ equiv), exhibiting a constant crystal size of approximately $100 \mathrm{~nm}$. Comparison of our results with the results of Schaate et al. ${ }^{26}$ leads to the conclusion that the influence of the modulator on crystal size is not straightforward and has to be taken into account during the material development. However, the results shown here clearly exhibit that the adsorption of uremic toxins over a metal-organic framework is influenced by numerous factors optimized during the synthesis procedure. Considering multiparameter approach in the optimization of UiO-66-based materials including defect engineering and -amino functionalization and combined approach, the interaction between the uremic toxin and the adsorption center and the interaction between the uremic toxin and the MOF structure seem to have a profound effect. ${ }^{9}$

The analysis of the thermogravimetric profiles for pristine and -amino-functionalized UiO-66 samples showed that the MOF decomposition temperature increases with decreasing $\mathrm{H}_{2} \mathrm{BDC}-\mathrm{NH}_{2}$ loading during mixed-linker synthesis, which is in good agreement with Chavan et al. ${ }^{21}$ Randomly distributed linkers in mixed-linker UiO- $\mathrm{NH}_{2}$ materials, i.e., $\mathrm{UiO}-66-\mathrm{NH}_{2}$, $\mathrm{UiO}-66-\mathrm{NH}_{2}(75 \%) 12.5 \% \mathrm{HCl}$, and $\mathrm{UiO}-66-\mathrm{NH}_{2}$ (75\%) $25 \%$ $\mathrm{HCl}$ samples, were confirmed by the comparable TGA profiles and considerably different shapes of DSC curves. ${ }^{21}$ However, it must be pointed out that despite the fact that both $\mathrm{UiO}-66$ $\mathrm{NH}_{2}(75 \%) 12.5 \% \mathrm{HCl}$ and $\mathrm{UiO}-66-\mathrm{NH}_{2}(75 \%) 25 \% \mathrm{HCl}$ samples showed similar TGA trends, both samples are evidently rich in structural defects, which is confirmed by the lower TGA curve in comparison to parent $\mathrm{UiO}-66-\mathrm{NH}_{2}(75 \%)$ (cf. Figure S5). ${ }^{21}$

Complementary information on the structure of the received materials is provided by the results of dissolution $/{ }^{1} \mathrm{H}$ NMR. The dissolution $/{ }^{1} \mathrm{H}$ NMR method proposed by Shearer et al. ${ }^{28}$ provides information about the impurities that may be incorporated into the MOF framework during the modulated synthesis. According to Shearer et al., ${ }^{28}$ the modulated samples may be contaminated with a considerable amount of monocarboxylic modulator or from DMF used as a solvent, which hydrolyzed to formate and dimethylamine in a highly basic $1 \mathrm{M} \mathrm{NaOH}$ medium. Despite the fact that our samples were activated at $200{ }^{\circ} \mathrm{C}$, which successfully removed both formates and dimethylamine from UiO-66 pores, acetates and formates are still present in small amounts in -aminofunctionalized samples. The reason for that is unknown; however, we can speculate that there is a strong interaction between formates and -amino groups inside the UiO-66- $\mathrm{NH}_{2}$ framework. A comparison of the modulator/BDC, formate/ $\mathrm{BDC}$, and total modulator/BDC ratio (Table S3) confirms the presence of acetates and formates in the MOF framework. The comparison of total modulator/BDC ratios found in the work by Shearer et al. ${ }^{28}$ and the results in this study is justified only for $\mathrm{UiO}-66$ prepared with the addition of $9.2 \mathrm{~mL}$ of acetic acid and the sample denoted by Shearer et al. ${ }^{28}$ as UiO-66 36 Ac. synthesized by the addition of $7.626 \mathrm{~mL}$ of acetic acid during the modulated synthesis. The modulator/BDC ratio in both samples was at a similar level except the acetate/BDC ratio, which is twice higher in the case of our sample. The reason for that is the derivative of $2 \mathrm{~mL}$ more volume of acetic acid used in the case of UiO-66. The acetate/BDC ratio oscillates around 0.19 , with the exception of $\mathrm{UiO}-66-\mathrm{NH}_{2}(100 \%)$, where it reaches the value of 0.33 . The increased content of acetates in the framework is most likely caused by the reduced average pore diameter determined, which makes it difficult to wash out and activate the sample.

The results of the adsorption studies in conjunction with the analyses of their structure indicate that, in particular, functionalization with amino groups can have a positive effect on toxin uptake. Similar trends were observed in the case of 3indoleacetic acid. The defect provided in this case binding sites for toxins and higher adsorption efficiency. However, the correlation of the values of the parameters describing the pore space of the materials $\left(\mathrm{SSA}_{\mathrm{BET}}, V_{\text {micro }}\right.$ and $\left.D\right)$ here is not clearly related to their abilities in toxin adsorption (Figure S25A-C). Despite the possibility of optimizing the pore size in the MOF structure during modulated synthesis, increasing the pore volume considerably decreases the number of binding sites for the adsorption of uremic toxins. The reduced number of available adsorption centers and the presence of acetates and formates compensating structural defects result in a significant reduction in sorption capacity.

Additionally, as was previously described in the work by Kato et al., ${ }^{9}$ the great sorption capacity of $p$-cresyl sulfate over NU-1000 is caused by electrostatic and $\pi-\pi$ interactions between uremic toxin and pyrene linker in NU-1000. As demonstrated, the $p$-cresyl sulfate adsorption on the NU-1000 occurred on hydrophobic adsorption sites located close to $\mathrm{Zr}_{6}$ hydroxyl groups, which were able to bond sulfate groups of the adsorbate by hydrogen bonding. In this study, as well as $\pi-\pi$ interactions between adsorbed uremic toxins and $\mathrm{H}_{2} \mathrm{BDC}$ in the case of UiO-66, we also observed maximization of the adsorption efficiency in the -amino functionalization of the UiO-66 structure and the synergic effect of amino functionalization and defect generation. The former is clearly visible for the adsorption of 3-indoleacetic acid over $\mathrm{UiO}-66-\mathrm{NH}_{2}$ (75\%) $12.5 \% \mathrm{HCl}$, where both -amino functionalization and defect generation were optimized. Moreover, the adsorption of hippuric acid over $\mathrm{UiO}-66-\mathrm{NH}_{2}(25 \%)$ and $\mathrm{UiO}-66-\mathrm{NH}_{2}$ $(100 \%)$ demonstrates that the adsorption capacity is influenced by the number of -amino groups substituted to the UiO-66- $\mathrm{NH}_{2}$ structure. Two extreme values of the -amino groups (25 and 100\%) in functionalized $\mathrm{UiO}-66-\mathrm{NH}_{2}$ show that the maximum adsorption values in the case of hippuric acid are achieved by complete substitution of $\mathrm{H}_{2} \mathrm{BDC}$ by $\mathrm{H}_{2} \mathrm{BDC}-\mathrm{NH}_{2}$. However, the adsorption of 3-indoleacetic acid indicates that this molecule requires the adsorbed structure to be optimized in both -amino substitution and defect generation by modulated synthesis with $\mathrm{HCl}$. The comparison of modeled electron densities for "defect-free" (Figure S26) and missing-linker (Figure S27), missing node (Figure S28), and missing-linker and node UiO-66 (Figure S29) would at first glance suggest the profound effect on defect generation of adsorption efficiency. The generated defect associated with linker/node removal through modulated synthesis generated void spaces, which increases the overall adsorption capacity ${ }^{18}$ through the generation of wider channels in the UiO-66 structure (cf. pore size distribution, Figure S4 insets). Indeed, the complete understanding of the mechanisms of the uremic toxins over modified UiO-66 samples would require in-depth DFT studies on the adsorption sites and the location of guest molecules in prepared materials. ${ }^{9,35}$

In considering the potential application of MOF materials for artificial kidney purposes, the uremic toxin adsorption ability should be considered on composite materials through 
which the blood will be passing during the hemodialysis. The recent work by Abdelhameed et al. ${ }^{19}$ describes the synthesis route of the preparation of UiO-66- $(\mathrm{COOH})_{2}$ that was grown directly on cotton fabric. The resulting UiO-66-(COOH $)_{2} @$ cotton fabric composite was tested in the adsorption of creatinine. The high adsorption efficiencies obtained by Abdelhameed et al. ${ }^{19}$ cannot be compared with the results from this study due to the differences between creatinine, hippuric acid, and 3-indoloacetic acid. However, in our opinion, the results from the work of Kato et al., ${ }^{9}$ Abdelhameed et al., ${ }^{19}$ and our own work suggest that achieving high sorption effects of uremic toxins will require the use of a composite material consisting of a series of MOFs selectively adsorbing a given family of uremic toxins. Therefore, in our opinion, a potential solution should have high sorption parameters, low cytotoxicity, and hemotoxicity as well as the ease of MOF material synthesis and low material cost.

Apart from optimizing the structure of MOF through its modulated synthesis and introducing functional groups, an important parameter is its cytotoxicity and hemotoxicity. Both of these factors are limiting in the search for new materials for artificial kidney applications. Since the results of cytotoxicity are quite obvious, the hemolytic activity of prepared samples should be discussed. In blood samples incubated with UiO-66 and related materials, a change can be observed in the shape of the RBC membrane characterized by numerous small, evenly spaced spikes (they look like sea urchins). Such a change of erythrocytes shape is called echinocytosis and is a reversible condition of RBCs, often caused by the presence of anticoagulant (mainly EDTA) or, as in our case, developed during hemolysis. The number of echinocytes is related to the increase in viscosity of blood that occurs during hemolysis. Echinocytes return to their normal RBC shape as the hemolytic factor is removed from direct contact with blood. This condition, together with cytotoxicity results, is the final confirmation of the low toxicological profile of the presented UiO-66 samples.

\section{CONCLUSIONS}

The influence of mixed-linker synthesis of UiO-66 to obtain $\mathrm{UiO}-66-\mathrm{NH}_{2}$ materials varying with the final content of -amino groups together with modulated synthesis with $\mathrm{HCl}$ on adsorption efficiency of uremic toxins was investigated in this study. The optimization of synthesis parameters such as the $\mathrm{H}_{2} \mathrm{BDC} / \mathrm{H}_{2} \mathrm{BDC}-\mathrm{NH}_{2}$ ratio and the amount of concentrated $\mathrm{HCl}$ at the preparation step allowed crystalline $\mathrm{UiO}-66$ $\mathrm{NH}_{2}$ materials with high uremic toxin sorption capacities to be obtained. The maximum sorption capacity for hippuric acid was achieved for $\mathrm{UiO}-66-\mathrm{NH}_{2}$ with 25 and $75 \mathrm{~mol} \%$-amino groups substituted in the UiO-66 structure and channels within the 5-9 and 14-18 $\AA$ ranges. The maximum adsorption capacity for 3-indoloacetic acid was achieved for UiO-66- $\mathrm{NH}_{2}$ (75\%) $\mathrm{HCl}$ and modulated $\mathrm{UiO}-66-\mathrm{NH}_{2}(75 \%) 12.5 \% \mathrm{HCl}$ samples with pores in the ranges of 5-8 and 17-22 $\AA$, respectively. Compared with the $\mathrm{Zr}$ MOF materials with the same topology, the obtained $\mathrm{UiO}-66$ and modified UiO-66$\mathrm{NH}_{2}$ samples reveal analogous sorption capacity to NU-1000. The adsorption isotherms for hippuric acid and 3-idoloacetic acid were fitted to the Langmuir and Freundlich models to obtain kinetic parameters. An almost linear correlation of both uremic toxins to the Freundlich model was found.

The uremic toxin adsorption results for modified UiO-66 and UiO-66- $\mathrm{NH}_{2}$ materials prepared by mixed-linker modu- lated synthesis show that appropriate modification of the synthesis step to obtain defective amino-functionalized UiO-66 materials is a key step in the preparation of efficient sorbents for uremic toxins. The cytotoxicity tests performed over HaCaT, Vero, HEK-293, and RBCs cells showed that the prepared UiO-66 samples revealed no cytotoxic effect. Furthermore, their cytoprotective effect against hippuric and 3 -indoloacetic acid as a model uremic toxin has proven that they can be considered as potentially safe for hemodialytic purposes.

In conclusion, for the first time, we have described a complementary approach for the synthesis, characterization, and in vitro toxicological evaluation of UiO-66-based materials for dialysis purposes. And the outcomes positively anticipate further study in this field.

\section{ASSOCIATED CONTENT}

\section{Supporting Information}

The Supporting Information is available free of charge at https://pubs.acs.org/doi/10.1021/acsami.1c05972.

Experimental details; characterization details; PXRD patterns for prepared $\mathrm{UiO}-66$ and $\mathrm{UiO}-66-\mathrm{NH}_{2}$ samples; UV-Vis absorbance spectra of UiO-66- $\mathrm{NH}_{2}(X \%)$ and $\mathrm{UiO}-66-\mathrm{NH}_{2}(X \%) \mathrm{Y} \% \mathrm{HCl}$ samples diluted in $1 \mathrm{M}$ aq. $\mathrm{NaOH}$ used for the determination of $\mathrm{H}_{2} \mathrm{BDC}-\mathrm{NH}_{2}$; lowtemperature $\mathrm{N}_{2}$ sorption isotherms; TGA/DSC results; in situ DRIFT; dissolution ${ }^{1} \mathrm{H}$ NMR spectra; DR UVVis spectra of prepared samples; hydrodynamic particle size distribution; adsorption efficiency of $1 \mathrm{mg}$ of prepared UiO-66 samples in $1.5 \mathrm{~mL}$ of $0.1 \mathrm{mM}$ hippuric acid as a function of time; pseudo-first-order kinetic model of adsorption of hippuric acid on the prepared UiO-66 samples; pseudo-second-order kinetic model of adsorption of hippuric acid on the prepared UiO-66 samples; adsorption efficiency of $1 \mathrm{mg}$ of prepared UiO66 samples in $1.5 \mathrm{~mL}$ of $0.1 \mathrm{mM} 3$-indoloacetic acid as a function of time; pseudo-first-order kinetic model of adsorption of 3-indoloacetic acid on the prepared $\mathrm{UiO}$ 66 samples; pseudo-second-order kinetic model of adsorption of 3 -indoloacetic acid on the prepared UiO-66 samples; Langmuir and Freundlich plots for hippuric acid and 3-indoloacetic acid for selected samples; synthesis details of mixed-linker defective UiO-66 samples; UV-Vis quantitative analysis results of $\mathrm{H}_{2} \mathrm{BDC}-\mathrm{NH}_{2}$; kinetic parameters of pseudo-first-order and pseudo-second-order models for hippuric acid; kinetic parameters of pseudo-first-order and pseudosecond-order models for 3-indoloacetic acid; Langmuir and Freundlich parameters for the adsorption of uremic toxins on the prepared MOF samples; 3-indoloacetic acid adsorption recyclability; images of Vero cells stained with H\& E; images of HEK-293 cells stained with $\mathrm{H} \& \mathrm{E}$; correlations between toxin removal efficiencies with structural parameters; structural model of "defect-free" UiO-66; structural model of UiO-66 missing-linker regions; structural model of UiO-66 missing node regions; and structural model of $\mathrm{UiO}-66$ missing-linker and missing node regions (PDF) 


\section{AUTHOR INFORMATION}

\section{Corresponding Author}

Przemysław J. Jodłowski - Faculty of Chemical Engineering and Technology, Cracow University of Technology, 30-155 Kraków, Poland; 이이.org/0000-0003-2554-6539; Email: pjodlowski@pk.edu.pl

\section{Authors}

Klaudia Dymek - Faculty of Chemical Engineering and Technology, Cracow University of Technology, 30-155 Kraków, Poland

Grzegorz Kurowski - Faculty of Chemical Engineering and Technology, Cracow University of Technology, 30-155 Kraków, Poland

Eukasz Kuterasinski - Jerzy Haber Institute of Catalysis and Surface Chemistry, Polish Academy of Sciences, 30-239 Kraków, Poland

Roman Jędrzejczyk - Małopolska Centre of Biotechnology, Jagiellonian University, 30-387 Kraków, Poland

Magdalena Szumera - Faculty of Materials Science and Ceramics, AGH University of Science and Technology, 30059 Kraków, Poland

Maciej Sitarz - Faculty of Materials Science and Ceramics, AGH University of Science and Technology, 30-059 Kraków, Poland; o orcid.org/0000-0002-8339-2710

Anna Pajdak - Strata Mechanics Research Institute, Polish Academy of Sciences, 30-059 Kraków, Poland

Eukasz Kurach - Independent Laboratory of Behavioral Studies, Medical University of Lublin, 20-093 Lublin, Poland; orcid.org/0000-0002-1005-8068

Anna Boguszewska-Czubara - Department of Medical Chemistry, Medical University of Lublin, 20-093 Lublin, Poland

Complete contact information is available at: https://pubs.acs.org/10.1021/acsami.1c05972

\section{Notes}

The authors declare no competing financial interest.

\section{ACKNOWLEDGMENTS}

This study was financially supported by B $+\mathrm{N}$ statutory funds from the Cracow University of Technology, Faculty of Chemical Engineering and Technology. Thermal studies were performed within the framework of funding for statutory activities of AGH University of Science and Technology in Krakow, Faculty of Materials Science and Ceramics (16.16.160.557).

\section{REFERENCES}

(1) Steddon, S.; Chesser, A.; Cunningham, J.; Ashman, N. Oxford Handbook of Nephrology and Hypertension; Oxford University Press, 2014.

(2) Vanholder, R.; De Smet, R.; Glorieux, G.; Argilés, A.; Baurmeister, U.; Brunet, P.; Clark, W.; Cohen, G.; De Deyn, P. P.; Deppisch, R.; Descamps-Latscha, B.; Henle, T.; Jörres, A.; Lemke, H. D.; Massy, Z. A.; Passlick-Deetjen, J.; Rodriguez, M.; Stegmayr, B.; Stenvinkel, P.; Tetta, C.; Wanner, C.; Zidek, W. Review on Uremic Toxins: Classification, Concentration, and Interindividual Variability. Kidney Int. 2003, 63, 1934-1943.

(3) Salani, M.; Roy, S.; Fissell, W. H. Innovations in Wearable and Implantable Artificial Kidneys. Am. J. Kidney Dis. 2018, 72, 745-751.

(4) Wernert, V.; Schäf, O.; Ghobarkar, H.; Denoyel, R. Adsorption Properties of Zeolites for Artificial Kidney Applications. Microporous Mesoporous Mater. 2005, 83, 101-113.
(5) Yen, S. C.; Liu, Z. W.; Juang, R. S.; Sahoo, S.; Huang, C. H.; Chen, P.; Hsiao, Y. S.; Fang, J. T. Carbon Nanotube/Conducting Polymer Hybrid Nanofibers as Novel Organic Bioelectronic Interfaces for Efficient Removal of Protein-Bound Uremic Toxins. ACS Appl. Mater. Interfaces 2019, 11, 43843-43856.

(6) Pavlenko, D.; Giasafaki, D.; Charalambopoulou, G.; Van Geffen, E.; Gerritsen, K. G. F.; Steriotis, T.; Stamatialis, D. Carbon Adsorbents with Dual Porosity for Efficient Removal of Uremic Toxins and Cytokines from Human Plasma. Sci. Rep. 2017, 7, No. 14914.

(7) Abdelhameed, R. M.; Rehan, M.; Emam, H. E. Figuration of ZrBased MOF@cotton Fabric Composite for Potential Kidney Application. Carbohydr. Polym. 2018, 195, 460-467.

(8) Cuchiaro, H.; Thai, J.; Schaffner, N.; Tuttle, R. R.; Reynolds, M. Exploring the Parameter Space of P-Cresyl Sulfate Adsorption in Metal-Organic Frameworks. ACS Appl. Mater. Interfaces 2020, 12, 22572-22580.

(9) Kato, S.; Otake, K.; Chen, H.; Akpinar, I.; Buru, C. T.; Islamoglu, T.; Snurr, R. Q.; Farha, O. K. Zirconium-Based Metal-Organic Frameworks for the Removal of Protein-Bound Uremic Toxin from Human Serum Albumin. J. Am. Chem. Soc. 2019, 141, 2568-2576.

(10) Yang, C. X.; Liu, C.; Cao, Y. M.; Yan, X. P. Metal-Organic Framework MIL-100(Fe) for Artificial Kidney Application. RSC Adv. 2014, 4, 40824-40827.

(11) Abdelhameed, R. M.; Abdel-Gawad, H.; Emam, H. E. Macroporous Cu-MOF@cellulose Acetate Membrane Serviceable in Selective Removal of Dimethoate Pesticide from Wastewater. J. Environ. Chem. Eng. 2021, 9, No. 105121.

(12) Abdelhameed, R. M.; Alzahrani, E.; Shaltout, A. A.; Emam, H. E. Temperature-Controlled-Release of Essential Oil via Reusable Mesoporous Composite of Microcrystalline Cellulose and Zeolitic Imidazole Frameworks. J. Ind. Eng. Chem. 2021, 94, 134-144.

(13) Emam, H. E.; Abdelhameed, R. M.; Ahmed, H. B. Adsorptive Performance of MOFs and MOF Containing Composites for Clean Energy and Safe Environment. J. Environ. Chem. Eng. 2020, 8, No. 104386.

(14) Emam, H. E.; Ahmed, H. B.; El-Deib, H. R.; El-Dars, F. M. S. E.; Abdelhameed, R. M. Non-Invasive Route for Desulfurization of Fuel Using Infrared-Assisted MIL-53(Al)-NH2 Containing Fabric. J. Colloid Interface Sci. 2019, 556, 193-205.

(15) Abdelhameed, R. M.; El-Shahat, M.; Emam, H. E. Employable Metal (Ag \& Pd)@MIL-125-NH2@cellulose Acetate Film for VisibleLight Driven Photocatalysis for Reduction of Nitro-Aromatics. Carbohydr. Polym. 2020, 247, No. 116695.

(16) Abdelhameed, R. M.; El-Shahat, M.; Emam, H. E. Employable Metal (Ag \& Pd)@MIL-125-NH2@cellulose Acetate Film for VisibleLight Driven Photocatalysis for Reduction of Nitro-Aromatics. Carbohydr. Polym. 2020, 247, No. 116695.

(17) Emam, H. E.; Ahmed, H. B.; Gomaa, E.; Helal, M. H.; Abdelhameed, R. M. Recyclable Photocatalyst Composites Based on Ag3VO4 and Ag2WO4@MOF@cotton for Effective Discoloration of Dye in Visible Light. Cellulose 2020, 27, 7139-7155.

(18) Jodłowski, P. J.; Kurowski, G.; Kuterasiński, Ł.; Sitarz, M.; Jeleń, P.; Jaśkowska, J.; Kołodziej, A.; Pajdak, A.; Majka, Z.; Boguszewska-Czubara, A. Cracking the Chloroquine Conundrum: The Application of Defective UiO-66 Metal-Organic Framework Materials to Prevent the Onset of Heart Defects-In Vivo and In Vitro. ACS Appl. Mater. Interfaces 2021, 13, 312-323.

(19) Abdelhameed, R. M.; Rehan, M.; Emam, H. E. Figuration of ZrBased MOF@cotton Fabric Composite for Potential Kidney Application. Carbohydr. Polym. 2018, 195, 460-467.

(20) Zhu, J.; Wu, L.; Bu, Z.; Jie, S.; Li, B. G. PolyethyleneimineModified UiO-66-NH 2 (Zr) Metal-Organic Frameworks: Preparation and Enhanced CO 2 Selective Adsorption. ACS Omega 2019, 4, 3188-3197.

(21) Chavan, S. M.; Shearer, G. C.; Svelle, S.; Olsbye, U.; Bonino, F.; Ethiraj, J.; Lillerud, K. P.; Bordiga, S. Synthesis and Characterization of Amine-Functionalized Mixed-Ligand Metal-Organic Frameworks of UiO-66 Topology. Inorg. Chem. 2014, 53, 9509-9515. 
(22) Kleist, W.; Jutz, F.; Maciejewski, M.; Baiker, A. Mixed-Linker Metal-Organic Frameworks as Catalysts for the Synthesis of Propylene Carbonate from Propylene Oxide and CO2. Eur. J. Inorg. Chem. 2009, 3552-3561.

(23) Han, Y.; Liu, M.; Li, K.; Zuo, Y.; Wei, Y.; Xu, S.; Zhang, G.; Song, C.; Zhang, Z.; Guo, X. Facile Synthesis of Morphology and Size-Controlled Zirconium Metal-Organic Framework UiO-66: The Role of Hydrofluoric Acid in Crystallization. CrystEngComm 2015, 17, 6434-6440.

(24) Pankajakshan, A.; Sinha, M.; Ojha, A. A.; Mandal, S. WaterStable Nanoscale Zirconium-Based Metal-Organic Frameworks for the Effective Removal of Glyphosate from Aqueous Media. ACS Omega 2018, 3, 7832-7839.

(25) Ni, B.; Sun, W.; Kang, J.; Zhang, Y. Understanding the Linear and Second-Order Nonlinear Optical Properties of UiO-66-Derived Metal-Organic Frameworks: A Comprehensive DFT Study. J. Phys. Chem. C 2020, 124, 11595-11608.

(26) Schaate, A.; Roy, P.; Godt, A.; Lippke, J.; Waltz, F.; Wiebcke, M.; Behrens, P. Modulated Synthesis of Zr-Based Metal-Organic Frameworks: From Nano to Single Crystals. Chem. - Eur. J. 2011, 17, 6643-6651.

(27) Clark, C. A.; Heck, K. N.; Powell, C. D.; Wong, M. S. Highly Defective UiO-66 Materials for the Adsorptive Removal of Perfluorooctanesulfonate. ACS Sustainable Chem. Eng. 2019, 7, 6619-6628.

(28) Shearer, G. C.; Chavan, S.; Bordiga, S.; Svelle, S.; Olsbye, U.; Lillerud, K. P. Defect Engineering: Tuning the Porosity and Composition of the Metal-Organic Framework UiO-66 via Modulated Synthesis. Chem. Mater. 2016, 28, 3749-3761.

(29) Wilson, V. G. Growth and Differentiation of $\mathrm{HaCaT}$ Keratinocytes. In Epidermal Cells: Methods and Protocols; Turksen, K., Ed.; Springer: New York, NY, 2014; pp 33-41.

(30) Buehler, P. W.; D'Agnillo, F. Toxicological Consequences of Extracellular Hemoglobin: Biochemical and Physiological Perspectives. Antioxid. Redox Signaling 2010, 12, 275-291.

(31) Lu, S.; Duffin, R.; Poland, C.; Daly, P.; Murphy, F.; Drost, E.; MacNee, W.; Stone, V.; Donaldson, K. Efficacy of Simple Short-Term in Vitro Assays for Predicting the Potential of Metal Oxide Nanoparticles to Cause Pulmonary Inflammation. Environ. Health Perspect. 2009, 117, 241-247.

(32) Liu, L.; Chen, Z.; Wang, J.; Zhang, D.; Zhu, Y.; Ling, S.; Huang, K. W.; Belmabkhout, Y.; Adil, K.; Zhang, Y.; Slater, B.; Eddaoudi, M.; Han, Y. Imaging Defects and Their Evolution in a Metal-Organic Framework at Sub-Unit-Cell Resolution. Nat. Chem. 2019, 11, 622628.

(33) Winarta, J.; Shan, B.; McIntyre, S. M.; Ye, L.; Wang, C.; Liu, J.; $\mathrm{Mu}, \mathrm{B}$. A Decade of UiO-66 Research: A Historic Review of Dynamic Structure, Synthesis Mechanisms, and Characterization Techniques of an Archetypal Metal-Organic Framework. Cryst. Growth Des. 2020, 20, 1347-1362.

(34) Hao, L.; Li, X.; Hurlock, M. J.; Tu, X.; Zhang, Q. Hierarchically Porous UiO-66: Facile Synthesis, Characterization and Application. Chem. Commun. 2018, 54, 11817-11820.

(35) Kato, S.; Drout, R. J.; Farha, O. K. Isothermal Titration Calorimetry to Investigate Uremic Toxins Adsorbing onto MetalOrganic Frameworks. Cell Rep. Phys. Sci. 2020, 1, No. 100006. 